\section{IPS Spotlight}

Continuing our profile of the activity of each of the IPS branches and Special Interest Groups, and members of the IPS Board, in this issue we have a report from the West Midlands and Wessex branches and from the Audit and Surveillance Special Interest Group. We also meet our new President Professor Heather Loveday and learn about her vision for the future development of IPS.

\section{PROFILE: IPS President Heather Loveday and her vision for IPS \\ Picture}

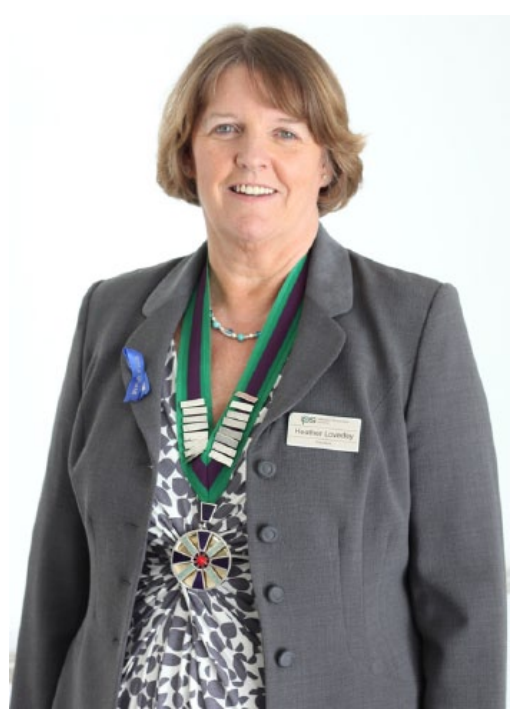

What is your background? I am a nurse by background. I qualified in 1979 at The Middlesex Hospital in London and then had several nursing posts including Ward Manager and Nursing Officer before going into nurse education in 1984. After several years of working as a Nurse Teacher and a Principal Lecturer at the Riverside College of Nursing based at Charing Cross Hospital in London, the NHS transferred all of its nursing education into a higher education setting, and that was when I moved into university education.

I came in as a Subject Quality Group Coordinator responsible for research and professional studies and moved into a research academic role in 1995.

\author{
Journal of Infection Prevention \\ 20I5, Vol. 16(2) 92-94 \\ DOI: $10.1|77 /| 757|774| 55754 \mid 3$ \\ (C) The Author(s) 2015 \\ Reprints and permissions: \\ sagepub.co.uk/journalsPermissions.nav \\ jip.sagepub.com
}

(SAGE
What is your current role and what does this entail? I work at the University of West London where I am the Director of the Richard Wells Research Centre and the Joanna Briggs Collaborating Centre, and Director of Research at the College of Nursing, Midwifery and Healthcare. My role is to lead on the research strategy and coordinate the activity within nursing, midwifery and healthcare so that we align our research work with national and local research agendas. My interest in infection prevention began when I worked with Professor Robert Pratt in the Centre for HIV and AIDS in the mid-1980s. Following the transfer into higher education we successfully tendered for a contract to write the first national evidence-based guidelines for preventing healthcare infections in 1998, commonly referred to as EPIC, and the rest is history, with the publication of the third Epic guidelines on the prevention of healthcare-associated infections in acute care settings in 2014. I believe this work is really important as it is essential that infection prevention practitioners understand the quality of the evidence base from which they practise. It has also helped to drive several research questions by identifying gaps or areas where evidence is not as strong. I have also conducted research in other key areas of infection prevention practice and Government policy, including the CHART study with Dr Evonne Curran, an evaluation of the meticillin-resistant Staphylococcus aureus (MRSA) improvement programme, the role of uniforms in transmission of HCAI and our most recent work with Dr Jennie Wilson about the inappropriate use of gloves in healthcare settings.

Can you tell us about your association with IPS and the plans for your term as President? I love being a member of IPS, it makes sure that I stay very close to the issues faced by people working on the frontline and stops me becoming a boring academic. I joined the Infection Prevention Society in 1998 as an associate member when I acted as the Higher Education Adviser to the Education Committee. Around the same time I worked with the Community Forum on a large project, funded by the $\mathrm{DH}$ (England) that focused on the roles and responsibilities of community infection control nurses. I joined the R\&D group when it was formed and later became the coordinator. I have also been the editor of the journal and two years ago I was elected as the Vice President. 
The Society has changed and matured in the years I have been a member and my predecessors have all had their own vision of where the Society can become stronger and have worked with the Board and branch coordinators to bring that about. The IPS Board has been very strong in the past 15 years, taking some risks to transform the organisation and provide a solid foundation for its future stability and growth. I think the Society faces some challenges and in order to go from strength to strength we have to start address some of them. I think the first is to do with ensuring that our membership continues to grow; this is quite testing against the background of loss of IPC posts across the healthcare economy, we need to attract new IPCPs and also those other professionals who have a remit for patient safety. Our rationale for becoming IPS was to enable us to attract members from a wider pool of professionals and we must focus on making the Society and what we provide for the membership relevant to those groups. Our communications strategy over the past two years has increased our visibility and I think building on that will help. We also have to recognise that the model of branch meetings and study days is increasingly challenging for the branch teams. The number of staff who can be released from their working day is reducing and so we need to look at how technology might help us provide opportunities for interaction and learning while keeping the human element of face-to-face meetings.

The IPS Vision that 'no person is harmed by a preventable infection' drives everything that the Society does and is underpinned by our view that education is the key to delivering on our promise. Education is not just about delivering content or creating competence, although these are important; it has a broader purpose to develop enquiring minds that are able to use knowledge to guide behaviour, shape thinking and challenge the status quo. Those who know me will generally say that I am a little bit 'argumentative' - I was brought up that way and I had the luxury of being educated in an era that was not constrained by government interference in the curriculum. Working with Robert Pratt and other colleagues at the Richard Wells Research Centre polished my natural tendency for questioning to the point that it is just the way I operate. Enquiry means asking and seeking to answer questions. Networking and education are enabling activities that prevent silo mentality and assist practitioners to anticipate and respond to clinical challenges. Our aim to be the Society of choice for a wide range of professionals involved in infection prevention and control, many of whom work in environments that do not traditionally release staff for professional development, means that the role of standing committees and special interest groups are pivotal in creating the sense of purpose that underpins the notion of Society. I want to ensure that these groups are robust and fit for purpose and highlight their value to employers as effective networking and learning opportunities. If we do that it becomes easier to strengthen the ways that we engage members in research and implementation that is grounded in practice and patient experience and encourage them to share their findings through publication and presentation.

In my Vice President election vision I highlighted that IPS contributes to the support of less economically developed nations and healthcare systems through its membership of IFIC and the individual efforts of some members who work closely with IPC practitioners in other countries to share expertise and best practice. The Ebola crisis in West Africa has highlighted how important it is that we meet our strategic aim to 'lead, shape and inform the infection prevention agenda... internationally'. Managing the financial health of the IPS may constrain our aspirations in this direction. However, the Board and I want to explore how we help colleagues, who work in less favourable financial and clinical environments, to access our resources and improve patient care internationally.

Finally, when we had our 'blue sky day' several years ago, we used the Disney model for generating our ideas. One of those Disney ideas was that one day there would be a Royal College of Infection Prevention with membership and fellowship. That may be some way off but as a Board we are looking at models for professional accreditation that would fit with revalidation requirements for healthcare professionals and provide those working in IPC with an internationally recognised certification that might become a fellowship model. I have so many ideas, I'm not going to be able to fit them all into two years (but I am going to do my damnedest!).

\section{IPS West Midlands \\ Jo Ellison, West Midlands Branch Coordinator}

The West Midlands branch is a friendly, welcoming and diverse group who welcomes members from all professional backgrounds. Joanna Peasland (secretary), Craig Bradley (Treasurer) and myself are the branch officers and strive to ensure that our branch provides a valuable resource for the members. We meet four times a year at venues across the West Midlands and vary the time of the meetings to allow the greatest opportunity for members to attend. Each meeting includes a review of branch activity and feedback together with an educational session. We encourage members to bring along colleagues to increase awareness of the work the IPS undertake and promote the networking opportunities taking place across the branch. In addition, we hold a conference each summer where we welcome both members and non-members to provide education and awareness of the issues facing infection prevention and control.

We are proud to have several branch members who take on additional roles within the IPS: Kate Prevc, who is the co-chair of the research and development group, and both 
Michael Nevill and Tina Bradley who are members of the scientific group. Tina's years of expertise at the Hospital Infection Research Laboratory have been a valuable asset to the branch. Last year the branch held a four-day course for new IPNs that evaluated well and we will be looking to start the next course in Spring 2015. In addition the branch are keen to expand into working on projects to benefit the wider infection prevention and control arena and will be working closely with Kate on the developing work around standard precautions planned for 2015.

\section{IPS Wessex}

\section{Rachael Skates, Wessex Branch Coordinator}

Those of you with a bent towards History will know that Wessex ceased to exist as a political unit in 1066. We take the Wessex name to cover the IPS areas of Dorset, Hampshire and Sussex with a current membership of 89 full members. It is a pleasure to tell you about our plans. I became the Wessex coordinator towards the end of 2014 and this being my first appointment as a branch officer I find myself jumping right in at the deep end! However I never feel like I am about to sink as I have the great support of the branch Secretary Alison Young, Treasurer Caroline Gilfrin and the Educational Lead Tracy Palmcurrent. The Branch team all live and work in the Sussex part of Wessex and our aim for this coming year is to encourage more IPS members from across the wider Wessex patch to take up positions on the branch Board. We also aim to improve attendance at our branch meetings and to support this we have made the decision to hold all branch meetings this year at the same location in Southampton. The Novotel was chosen due to ease of access from any direction, free parking and not forgetting the great buffet provided for our meeting attendees.

To add value for our members, our meetings this year will include educational master classes as well as discussions around the other great benefits that IPS membership unlocks.

Other strategies we are exploring include the move towards modern modes of communication, as apparently Twitter is not a type of bird vocalisation but some form of social networking app. We are also looking to improving the branch content of the IPS website. I would also like to welcome on board our branch buddy Gary Thirkell. Gary comes to us with a wealth of experience from his Yorkshire group and with his support we are looking to strengthen our governance and meeting structure for the benefit of all IPS members. Finally I really recommend that members become actively involved and take up the roles within the team; it is a great learning curve and helps you develop professionally and personally.

\section{IPS Audit and Surveillance Special Interest Group \\ Pauline Harrington, Audit \& Surveillance Coordinator}

The Audit and Surveillance (A\&S) Special Interest Group (SIG) has a membership of 190, with myself, Dafydd Williams (Deputy Coordinator) and Sandra Beaumont (Secretary) as branch officers. The group has successfully organised educational meetings with presentations from members of IPS SIGs on Public Health England's Surgical Site Infection and Catheter Blood Stream Infection surveillance and an update on surveillance from Scotland.

A joint educational day was also organised involving three SIGs (Audit and Surveillance, Ambulance Services, and Mental Health and Learning Disability). When the three groups first met to plan this event there were questions around whether the day would meet the needs of the different memberships. We were able to find a way to make the presentations mesh and had an extremely successful day. The three SIGs are planning to repeat the educational day in 2015.

We have asked our members to complete a survey to establish whether the group is meeting their needs. Eighty percent of the respondents indicated that it did meet their needs, with the preferred venue being Birmingham and the majority $(90 \%)$ of the membership preferring to attend an event rather than webinar or Skype. The survey also captured very positive feedback about the joint SIG events indicating that they were informative, met their educational needs and was a good opportunity for networking and meeting with the exhibitors. During 2014 the group has finalised the A\&S competencies which are now available via JIP and the IPS website.

Our plans for 2015 include reviewing and strengthening our infrastructure, arranging more forum meetings, a newsletter and developing the website. We also plan to map all SIG activities to competencies, develop our research agenda, hold another joint SIG study day involving Ambulance and Mental Health \& Learning Disabilities SIGs, and collaborate on training with the London South Branch. 